\title{
Evaluation of Anthelmintic Efficacy of Nicotiana tabacum against Gastrointestinal Nematodes of Goats
}

\author{
Sushmita Sastya, Rajeev Ranajan Kumar* and Stuti Vatsya
}

\author{
College of Veterinary and Animal Sciences, G.B. Pant University of Agriculture and \\ Technology, Pantnagar-263145, Uttarakhand, India \\ *Corresponding author
}

Ke y w or d s
$\begin{aligned} & \text { Nicotiana tabacum, } \\ & \text { Anthelmintic } \\ & \text { activity, GI } \\ & \text { nematodosis, Goats. }\end{aligned}$
Article Info
$\begin{aligned} & \text { Accepted: } \\ & \text { 07 September } 2017 \\ & \text { Available Online: } \\ & 10 \text { October } 2017\end{aligned}$

Article Info

Accepted:

Available Online:

10 October 2017

\section{A B S T R A C T}

The present study was planned to evaluate the anthelmintic efficacy of crude powder (CP), crude aqueous (CAE) and crude methanolic (CME) extracts of Nicotiana tabacum leaves against common gastrointestinal nematodes of goats using three in-vitro tests viz. adult motility test (AMT), egg hatch assay (EHA) and larval paralysis test (LPT) and one invivo test using faecal egg count reduction test (FECRT). AMT was conducted against freshly collected adult Haemonchus contortus. However, EHA and LPT tests were conducted against eggs and larvae of gastrointestinal nematodes, respectively of goats or AMT at different concentrations viz. $0.156 \%, 0.312 \%, 0.625 \%, 1.25 \%, 2.5 \%, 5 \%$ and $10 \%$. In-vivo trial was also conducted in goats naturally infected with mixed infection of GI nematodes using FECRT. In AMT, an average highest corrected motility of $100 \%$ was recorded from $0.625-10 \%$ concentration followed by $66.66 \%$ at 0.156 and $0.312 \%$ concentrations. Overall $\mathrm{CP}$ and CAE showed maximum (100\%) adulticidal activity against H. contortus and minimum (71.43\%) with CME. In EHA, CME of N. tabacum showed better $\mathrm{ED}_{50}=0.522$ and $\mathrm{ED}_{99}=21.32 \mathrm{mg} / \mathrm{ml}$ in comparison to $\mathrm{CAE}\left(\mathrm{ED}_{50}=0.40\right.$ and $\mathrm{ED}_{99}=$ $36.22 \mathrm{mg} / \mathrm{ml})$. The highest $(100 \%)$ inhibition of egg hatching was observed with CAE @ 50 and $100 \mathrm{mg} / \mathrm{ml}$ and CME @ 25, 50 and $100 \mathrm{mg} / \mathrm{ml}$ concentration. In case of LPT, crude methanolic extract has better $\left(\mathrm{ED}_{50}=0.69\right.$ and $\left.\mathrm{ED}_{99}=9.58 \mathrm{mg} / \mathrm{ml}\right)$ values than crude aqueous extract $\left(\mathrm{ED}_{50}=0.759\right.$ and $\left.\mathrm{ED}_{99}=14.9349 \mathrm{mg} / \mathrm{ml}\right)$. The highest $(100 \%)$ paralysis of third stage larvae was observed with CAE @ 25, 50 and 100mg/ml and CME @ 12.5, 25, 50 and $100 \mathrm{mg} / \mathrm{ml}$ concentration. In in-vivo trial, the highest (100\%) reduction in faecal egg count was recorded against CAE @ both 100 and $200 \mathrm{mg} / \mathrm{kg}$ b. wt. 14 days post-treatment. However, CME and CP both showed maximum effect of $33.33 \%$ and $15.79 \%$, respectively @ $200 \mathrm{mg} / \mathrm{kg}$ b. wt. on 14 days post-treatment.

\section{Introduction}

Sheep and goats serve as major source of income for poor and landless farmers of Indian subcontinent, but the production performance of these animals is drastically reduced due to parasitic infections. Sheep and goats are highly susceptible to various helminth infections specially goats due to its unique grazing behaviour. Among nematodes,
Haemonchus contortus is the most pathogenic gastrointestinal (GI) nematode distributed in different agro-climatic regions throughout the year. It causes heavy economic losses in terms of retarded growth, weight loss, lowered productivity and even mortality (Tyasi and Tyasi, 2015). Several methods have been employed for controlling the 
infection that includes anthelmintic treatment (Singh and Yadav, 1997), nutritional management (Swarnkar and Singh, 2005), pasture management, biological control (Sanyal, 1998) and immunization (Smith, 2014). Use of chemical drugs remains the only option to control GI nematodosis under field condition because of unavailability and unfeasibility of the other methods of controlling the infection. Unfortunately, the excessive or haphazard use of chemical drugs had lead to emergence of resistance among the GI parasite in most of the countries including India (Rialch et al., 2013). Use of chemical drugs and emergence of resistance are the factors which are forcing the researchers to find out an alternative control methods. The exploitation of herbal product is a better option for most of small scale farmers as herbs having medicinal property are distributed in different regions of the country. Several plants available in India have been identified having anthelmintic activity (Bhardwaj et al., 2015; Kumar et al., 2014 and 2016). Major benefits of herbs based dewormers include broad spectrum activity, non-toxic with wide margin of safety, cheaper and supplementary effects on animal health (Kuamr et al., 2015).

Nicotiana tabacum having narcotic properties was originally native to America but now is cultivated in other countries including India and is locally known as tambacco. The ethno medical uses include use of the decoction of leaves as antispasmodics, expectorants, emetics, sedatives, and in rheumatic swellings, anesthetics, anticonvulsants, antibacterial, diuretics, antimicrobial, and for anti-fungal activities and anthelmintic activities (Nouri et al., 2014). Keeping in mind, the use of the plant in traditional medicine, the present study was planned to evaluate the anthelmintic activity of Nicotiana tabacum against different stages of GI nematodes.

\section{Materials and Methods}

\section{Selection of plant}

Leaves of Nicotiana tabacum were purchased from local market of Pantnagar. N. tabacum was selected, on the basis of their documented anthelmintic properties or literature survey on traditional uses in India and other parts of the world.

The authentication and identification of the plant was confirmed by Department of Biological Sciences, College of Basic Science and Humanities, G.B. Pant University of Agriculture and Technology, Pantnagar.

\section{Preparation of extract}

The leaves were air-dried under shade, coarsely grinded with the electric mixer grinder and stored in airtight container. Two extracts of the plant were prepared viz. Crude aqueous extract (CAE) and crude methanol extract (CME) using distilled water and methanol, respectively. About $50 \mathrm{gm}$ of powdered sample was soaked separately in $400 \mathrm{ml}$ of each solvent in 1 lit glass flasks, covered with aluminium foil and stirred every one hour interval initially for 2-3 times and left undisturbed for $8 \mathrm{hrs}$. At room temperature and then filtered by separating funnels using Whatman paper No.1. The filtrate was concentrated by using rotatory vacuum evaporator at $50-55^{\circ} \mathrm{C}$ (Singh, 2001).

The extract residues were individually marked, kept in airtight glass petridishes in refrigerator at $4^{0} \mathrm{C}$ till further use. Seven dilutions of each extract residues were prepared viz. $0.156 \%, 0.312 \%, 0.625 \%$, $1.25 \%, 2.5 \%, 5 \%$ and $10 \%$ in locks solution. Thiabendazole was dissolved in Dimethyl Sulfoxide (DMSO) and distilled water at same concentrations and used as positive control and. 
In-vitro evaluation of enthelmintic activity of $N$. tabacum

\section{Adult motility test}

\section{Collection of worms}

Adult Haemonchus contortus worms were procured from the abomasii of goats freshly slaughtered at Lalkuan slaughter house. The worms were washed with distilled water and then transferred in wide mouth glass container having lukewarm normal saline. Then after, the collected worms were brought to the laboratory, Department of Veterinary Parasitology, College of Veterinary \& Animal Sciences, Pantnagar. Several washings of the worms were made with normal saline solution and finally the worms were transferred in beaker containing Lock's solution and kept at $37^{\circ} \mathrm{C}$ in incubator to acclimatize before beginning the test (Bhatnagar et al., 1961)

For AMT, ten freshly collected adult $H$. contortus were taken in each small petridishes having $15 \mathrm{ml}$ of different dilutions of extracts and crude powder. Lock's solution was used as positive control. It was then incubated at $37^{\circ} \mathrm{C} \pm 1^{\circ} \mathrm{C}$ for $24 \mathrm{hrs}$ and number of live and dead adult worms were counted at $1,2,4,6$, 12,18 and $24 \mathrm{hrs}$ interval. The viability of the worms was determined by pinch technique (the absence of motility for an observation period of 5-6 second) as described by Neogi et al., (1964). The corrected mortality was calculated as per the formula given by Sangwan and Sangwan (1998).

Total mortality- Control mortality $\%$ corrected mortality $=$ X 100

Total mortality

\section{Egg hatch assay}

Gastrointestinal (GI) nematodes eggs were collected by using standardized protocol adopted by the World Association for
Advancement of Veterinary Parasitology (Coles et al., 1992). The egg hatch test was performed as per Le Jambre (1976). Faecal samples were collected from local goats naturally infected with GI nematodes in a screw top plastic bottle and stored an aerobically. The bottles were almost fully filled with water and were shaken vigorously. Faecal samples were broken in mortarpestle with water to make homogenised suspension. It was sieved through tea strainer of $0.15 \mathrm{~mm}$ aperture, $20 \mathrm{~cm}$ diameter and then filtrate was transferred into centrifuge tube $(15 \mathrm{ml})$. Then after, it was centrifuged for $2 \mathrm{~min}$. at $300 \times \mathrm{g}$ and then supernatant was gently sucked off. Tubes were agitated to loosen the sediment, then saturated salt solution was added into the tube up to $2 / 3 \mathrm{rd}$ and re-centrifuge for $3 \mathrm{~min}$ at $130 \times \mathrm{g}$. The tubes were filled with saturated salt solution until a meniscus was formed above the tube. A cover slip was gently placed above the meniscus by avoiding bubbles and left for few minutes. The cover slip was plucked off and the eggs were washed with deionised water into a conical centrifuge tube. These tubes were filled and the eggs were re-suspended in deionised water, the number of eggs were estimated per $\mathrm{ml}$ and diluted to 100 $150 / 100 \mu 1$. 100 $\mu 1$ of fresh egg suspension containing about 100-150 fresh eggs were placed in each well of 96-multiwell plate containing $1 \mathrm{ml}$ extract in multiwell plate, while control well received water instead of extract. Total volume of each well was made up to $2 \mathrm{ml}$ by adding $900 \mu \mathrm{l}$ of distilled water. Plates were incubated at $27^{\circ} \mathrm{C}$ for 48 hours. Two drops of Lugol's iodine were added to each well. A total of hundred eggs and hatched larvae were counted under compound microscope.

\section{Larval paralysis test}

Faecal samples were collected directly from rectum of the animals and transferred in 
faecal bags. The faecal sample collected from each group was pooled. Pooled sample was broken in a tray with spatula and mixed with adequate quantity of activated charcoal to avoid fermentation. The faeces were then packed loosely in petridish. The petridish was then incubated at $27^{\circ} \mathrm{C}$ in BOD incubator over a period of one week. The samples were kept moist by sprinkling water on every alternate day. The infective third stage larvae (L3 stages) were harvested by using Bearmann's apparatus (MAFF 1986). 100 $\mu 1$ containing 100-150 live larvae were exposed to different concentrations of extracts ranging from $0.156 \%-10 \%$ in 96 multiwell plates. After 24 hrs, live (motile) and dead larvae were counted.

\section{In-vivo evaluation of anthelmintic activity of N. tabacum}

\section{Location of study area}

Evaluation of anthelmintic efficacy of plant extracts residue was carried out in goats from Department of Livestock Production and Management, College of Veterinary and Animal Sciences, Pantnagar and also in local areas, Sanjay colony and Jha colony of Pantnagar.

\section{Grouping and treatment of animals}

Animals having faecal egg per gram of faeces more than 200 and also having the history of not using any kind of anthelmintic treatment since last three months were selected. Forty two goats naturally infected with mixed infections of gastrointestinal nematodes of either sex, aged between 1-3 years were selected, numbered and weighed during each trial.

These animals were randomly divided into seven group viz. GI, GII, GIII, GIV, GV, GVI and GVII comprising of 6 animals each.
The GI, GII and GIII groups were treated with crude powder (CP), crude aqueous (CAE) and crude methanolic (CME) extracts of Nicotiana leaves, resprctively @ $100 \mathrm{mg} / \mathrm{kg}$ b.wt. orally, while GIV, GV and GVI were treated @200mg/kg b.wt. orally with CP, $\mathrm{CAE}$ and CME, respectively. However, animals of GVII kept as untreated infected control.

\section{Faecal Egg Count Reduction Test (FECRT)}

Faecal egg count from individual animals of each treated and control groups were performed on 0 day (before) of treatment, 7 and 14 day post-treatment ( 7 and 14 DPT) using modified Mc Master egg counting technique.

Faecal suspension was prepared using one gram of faecal sample in $14 \mathrm{ml}$ saturated salt solution. Sample was sieved through tea strainer and transferred into plastic /glass test tube. Mc Master egg counting chamber of was charged and eggs of gastrointestinal nematodes were counted under 10X magnification of light microscope.

The intensity of egg per gram of faeces (EPG) was determined by modified Mc Master Technique (MAFF, 1971). The egg per gram of faeces was calculated as follows:

Egg per gram $(E P G)=$ Number of eggs in the chamber x 50

\section{Determination of anthelmintic efficacy}

The anthelmintic efficacy of the each extract residues was calculated using the following formula given by Dash et al., (1988)

EPG before treatment-EPG after treatment $\%$ efficacy $=$ x 100

EPG before treatment 


\section{Coproculture}

Pooled faecal samples of each group were cultured to harvest the third stage larvae according to MAFF (1971) using Baermanns apparatus. GI nematode larvae were identified on the basis of their morphological characters as described by Soulsby (1965).

\section{Phytochemical analysis of extracts}

Extract residues obtained from various solvents were tested for the presence of their phytoconstituents such as alkaloid, anthraquinones, tannins, flavonoids, saponins, glycoside, resins, triterpencs, reucing sugars, proteins and coumarins by standard procedures (Sofowara, 1982).

\section{Statistical analysis}

The data of in-vitro trials viz. Egg Hatch Assay and Larval Paralysis Test were analyzed statistically using probit analysis for calculation of $\mathrm{ED}_{50}$ and $\mathrm{ED}_{99}$ by SPSS version 16. However, multivariat two ways ANOVA was used to analyze the data for calculation of F-value obtained from in-vivo trials and difference between the means were considered significant at $\mathrm{p}>0.05$.

\section{Results and Discussion}

In the present study, anthelmintic activity of Nicotiana tabacum was assessed against adult Haemonchus contortus, eggs and larvae of common gastrointestinal nematodes using three tests viz. adult motility test (AMT), egg hatch assay (EHA) and larval paralysis test (LPT), respectively and faecal egg count reduction test (FECRT).

\section{Adult motility test}

$\mathrm{CP}$ and CAE extracts causes $100 \%$ mortality at all tested concentration viz. $0.156 \%$, $0.312 \%, 0.625 \%, 1.25 \%, 2.5 \%, 5 \%$ and $10 \%$ whereas CME showed 0, 0, 100, 100, 100, 100 and $100 \%$ mortality, respectively at $0.156 \%, 0.312 \%, 0.625 \%, 1.25 \%, 2.5 \%, 5 \%$ and $10 \%$ concentrations. Overall $\mathrm{CP}$ and $\mathrm{CAE}$ of $N$. tabacum showed $100 \%$ average corrected mortality while CME showed $71.43 \%$ only (Table 1). However, TBZ showed $100 \%$ mortality of the worms at $1.25 \%, 2.5 \%, 5 \%$ and $10 \%$ against all concentrations (Table 1).

An average highest corrected motility of $100 \%$ was observed from $0.625-10 \%$ followed by $66.66 \%$ at 0.312 and $0.156 \%$. Overall N. tabacum showed overall $94.47 \%$ corrected mortality (Table 2).

\section{Egg hatch assay}

CAE and CME extracts of $N$. tabacum caused significant inhibition of egg hatching with increasing dose (Table 3). CAE $\left(\mathrm{ED}_{50}=0.40\right.$ and $\mathrm{ED}_{99}=36.22 \mathrm{mg} / \mathrm{ml}$ ) @ 50 and $100 \mathrm{mg} / \mathrm{ml}$ concentration showed $100 \%$ inhibition. However, at 25.12.5, 6.25, 3.12 and 1.56 $\mathrm{mg} / \mathrm{ml}$ concentration, inhibition of egg hatching were 99, 95, 90, 84 and 79\%, respectively. $\mathrm{CME}\left(\mathrm{ED}_{50}=0.522\right.$ and $\mathrm{ED}_{99}=$ $21.320 \mathrm{mg} / \mathrm{ml})$ showed highest (100\%) inhibition of egg hatching at 25, 50 and $100 \mathrm{mg} / \mathrm{ml}$ concentration followed by 97,93 , 85 and $78 \%$ at $12.5, \quad 6.25 \quad 3.125$ and $1.56 \mathrm{mg} / \mathrm{ml}$ concentration, respectively (Tables 3 and 4). In EHA, TBZ showed 100\% inhibition in egg hatching at all concentrations (Table 2).

\section{Larval paralysis test}

CAE and CME extracts of $N$. tabacum causes significant dose dependent paralysis of third stage $\left(\mathrm{L}_{3}\right)$ larvae of GI nematodes. The CAE $\left(\mathrm{ED}_{50}=0.75\right.$ and $\left.\mathrm{ED}_{99}=14.34 \mathrm{mg} / \mathrm{ml}\right)$ caused $100 \%$ paralysis of third stage $\left(\mathrm{L}_{3}\right)$ larvae at 25,50 and $100 \mathrm{mg} / \mathrm{ml}$ concentration. However, it was 99, 94, 86 and $73 \%$ at 12.5 , $6.25,3.125$ and $1.56 \mathrm{mg} / \mathrm{ml}$, respectively. 
Crude methanolic $\left(\mathrm{ED}_{50}=0.69\right.$ and $\mathrm{ED}_{99}=$ $9.58 \mathrm{mg} / \mathrm{ml}$ ) extract also caused $100 \%$ paralysis of $\mathrm{L}_{3}$ larvae at 100, 50, 25 and 12.5 $\mathrm{mg} / \mathrm{ml}$ concentration, while at $6.25,3.125$ and $1.56 \mathrm{mg} / \mathrm{ml}$ concentration, it was 97,89 and $78 \%$, respectively (Tables 2 and 3). In LPT, TBZ caused $100 \%$ paralysis of third $\left(\mathrm{L}_{3}\right)$ stage larvae of gastrointestinal nematodes in all tested concentrations (Table 2).

\section{In-vivo anthelmintic efficacy of $N$. Tabacum using FECRT}

Anthelmintic efficacy of the plant extracts was conducted in goats found positive with mixed infection of GI nematodes. Coproculture examination revealed the presence of Haemonchus contortus as predominant GI nematode followed by Oesophagostomum columbianum, Trichostrongylus colubriformis and Strongyloides spp. The highest $(85.71 \%)$ reduction in faecal egg count was observed against CAE followed by CME (14.28\%) and CP $(-2.9 \%)$ on 7 DPT, however, it was 100 , 28.57 and $5.88 \%$ on 14 DPT following treatment @ 100mg/kg b.wt. orally.

CAE showed highest (90\%) reduction in faecal egg count followed by CME (25\%) and lowest (10.53\%) against CP on 7 day posttreatment while it was $100,33.33$ and $15.79 \%$, respectively on 14 day post-treatment @ $200 \mathrm{mg} / \mathrm{kg}$ b.wt. orally (Table 4). Nonsignificant difference was observed by $\mathrm{CP}$ and CME.

\section{Phytochemical analysis}

On phytochemical analysis, alkaloids, reducing sugar, saponin and tannins were found in CAE of $N$. tabacum. However, CME revealed the presence of alkaloids, coumarins, reducing sugar, saponin and tannins.

Table.1 Average \% corrected mortality of CP, CAE and CME of Nicotiana tabacum and TBZ against adult $H$. contortus

\begin{tabular}{|c|c|c|c|c|c|c|c|c|}
\hline \multirow[t]{2}{*}{ Extracts } & \multicolumn{7}{|c|}{ Average $\%$ mortality at different $\%$ concentration } & \multirow{2}{*}{$\begin{array}{c}\text { Average } \% \\
\text { CM }\end{array}$} \\
\hline & 0.156 & 0.312 & 0.625 & 1.25 & 2.5 & 5 & 10 & \\
\hline $\mathrm{CP}$ & 100 & 100 & 100 & 100 & 100 & 100 & 100 & 100 \\
\hline CAE & 100 & 100 & 100 & 100 & 100 & 100 & 100 & 100 \\
\hline CME & 0 & 0 & 100 & 100 & 100 & 100 & 100 & 71.43 \\
\hline TBZ & 0 & 0 & 0 & 100 & 100 & 100 & 100 & 57.14 \\
\hline
\end{tabular}

CP-crude powder, CAE- crude aqueous extract, CME- crude methanol extract

Table. $2 \%$ inhibition of egg hatching and larval paralysis at different concentrations of CAE and CME of N. tabacum and TBZ

\begin{tabular}{ccccccc}
\hline Concentration & \multicolumn{2}{c}{ \% inhibition of egg hatching } & \multicolumn{4}{c}{ \% of Larval paralysis } \\
\cline { 2 - 7 }$(\mathrm{mg} / \mathrm{ml})$ & CAE & CME & TBZ & CAE & CME & TBZ \\
1.56 & 79 & 78 & 100 & 73 & 78 & 100 \\
3.12 & 84 & 85 & 100 & 86 & 89 & 100 \\
6.25 & 90 & 93 & 100 & 94 & 97 & 100 \\
12.5 & 95 & 97 & 100 & 99 & 100 & 100 \\
25 & 99 & 100 & 100 & 100 & 100 & 100 \\
50 & 100 & 100 & 100 & 100 & 100 & 100 \\
100 & 100 & 100 & 100 & 100 & 100 & 100 \\
\hline
\end{tabular}


Table.3 ED ${ }_{50}$ and ED $99(\mathrm{mg} / \mathrm{ml})$ of CAE and CME of $N$. tabacum in EHA and LPT

\begin{tabular}{|c|c|c|c|c|c|c|c|}
\hline \multirow{2}{*}{$\begin{array}{c}\text { N. tabacum } \\
\text { extracts }\end{array}$} & \multirow[t]{2}{*}{ Tests } & \multicolumn{3}{|c|}{$\mathrm{ED}_{50} \mathrm{mg} / \mathrm{ml}$} & \multicolumn{3}{|c|}{$\mathrm{ED}_{99} \mathrm{mg} / \mathrm{ml}$} \\
\hline & & $\mathrm{ED}_{50}$ & $\begin{array}{c}\text { Lower } \\
\text { limit }\end{array}$ & $\begin{array}{l}\text { Upper } \\
\text { limit }\end{array}$ & $\mathrm{ED}_{99}$ & $\begin{array}{c}\text { Lower } \\
\text { limit }\end{array}$ & $\begin{array}{l}\text { Upper } \\
\text { limit }\end{array}$ \\
\hline CAE & EHA & 0.40 & 0.14 & 0.74 & 36.22 & 20.80 & 95.33 \\
\hline & LPT & 0.75 & 0.40 & 1.09 & 14.939 & 9.57 & 29.00 \\
\hline CME & EHA & 0.52 & 0.21 & 0.864 & 21.32 & 13.22 & 49.41 \\
\hline & LPT & 0.69 & 0.32 & 1.026 & 9.58 & 6.53 & 19.98 \\
\hline
\end{tabular}

Table.4 In-vivo anthelmintic efficacy of $N$. tabacum against mixed infection of GI nematodes in goats

\begin{tabular}{|c|c|c|c|c|c|c|c|}
\hline \multicolumn{2}{|c|}{ Groups } & GI & GII & GIII & GIV & GV & GVI \\
\hline \multicolumn{2}{|c|}{$\begin{array}{l}\text { Treatment \& dose } \\
\text { rate (per kg b.wt) }\end{array}$} & $\begin{array}{c}\mathrm{CP} \\
@ 100 \mathrm{mg}\end{array}$ & $\begin{array}{c}\text { CAE } \\
@ 100 \mathrm{mg}\end{array}$ & $\begin{array}{c}\mathrm{CME} \\
\text { @ } 100 \mathrm{mg}\end{array}$ & $\begin{array}{c}\mathrm{CP} \\
\text { @ } 200 \mathrm{mg}\end{array}$ & $\begin{array}{c}\mathrm{CAE} \\
\text { @ } 200 \mathrm{mg}\end{array}$ & $\begin{array}{c}\mathrm{CME} \\
\text { @ 200mg }\end{array}$ \\
\hline \multirow{2}{*}{$\begin{array}{c}\% \\
\text { FECRT }\end{array}$} & (7DPT) & -2.9 & 85.71 & 14.28 & 10.53 & 90 & 25 \\
\hline & (14DPT) & 5.88 & 100 & 28.57 & 15.79 & 100 & 33.33 \\
\hline
\end{tabular}

AMT of $N$. tabacum against $H$. contortus revealed that both $\mathrm{CP}$ and $\mathrm{CAE}$ showed maximum (100\%) adulticidal activity against $H$. contortus followed by $(71.43 \%)$ CME. Adulticidal activity of the decoction of $N$. tabacum against $H$. contortus has also been observed by Raje and Jangde (2003). However, Sindhu et al., (2014) observed $100 \%$ mortality against aqueous extract slightly at higher concentration. $100 \%$ mortality of $H$. contortus against aqueous and methanolic extracts @25, 50 and $100 \mathrm{mg} / \mathrm{ml}$ has been also observed by Iqbal et al., (2006).

EHA trial of $N$. tabacum revealed that CME showed better $\mathrm{ED}_{99}$ value $(21.320 \mathrm{mg} / \mathrm{ml})$ in comparison to CAE $(36.225 \mathrm{mg} / \mathrm{ml})$. CME also showed maximum inhibition in egg hatching at lower concentration than CAE. The dose-dependent ovicidal activity of the plant has also been reported by Hamad et al., (2012).

The findings of LPT revealed that CME has better $\mathrm{ED}_{50}$ and $\mathrm{ED}_{99}\left(\mathrm{ED}_{50}=0.696\right.$ and $\mathrm{ED}_{99}=$ $9.585 \mathrm{mg} / \mathrm{ml})$ values than $\mathrm{CAE}\left(\mathrm{ED}_{50}=0.759\right.$ and $\mathrm{ED}_{99}=14.349 \mathrm{mg} / \mathrm{ml}$ ) and also showed dose-dependent activity of larval paralysis. Larvicidal activity of the aqueous extract of Nicotiana has also been reported by Molef $e t$ al., (2013).

In-vivo trials revealed that CAE showed $100 \%$ efficacy in goats naturally infected with mixed infections of GI nematodes at both 100 and $200 \mathrm{mg} / \mathrm{kg}$ body wt. orally. Iqbal et al., (2006) recorded $49.4 \%$ and $73.6 \%$ reduction in faecal egg counts in sheep naturally parasitized with gastrointestinal nematodes following treatment with crude aqueous and methanolic extracts @ $3 \mathrm{mg} / \mathrm{kg}$ b. wt. on 5 days post-treatment However, Hamad et al., (2012) observed $87.5 \%$ and $88.6 \%$ reduction in faecal egg count against crude aqueous methanolic extracts@2mg and 4mg/kg b.wt., respectively.

Anthelmintic effectiveness of $N$. tabacum occurs due to the presence of excitatory neuromuscular junctions containing ganglion type nicotinic receptors with acetylcholine as their neurotransmitter present in muscles of nematode parasites (Neal, 2002). The ganglion stimulant nicotine is known to found 
in $N$. tabacum leaves and it activates these neuromuscular junctions causing spastic paralysis in the worm results into death and expulsion of the worms from the host (Bowman and Rand, 1980). Kambou and Guissou (2011) observed that aqueous extract contains alkaloids, steroids, saponins, tannins and triterpins. However, Kaushik et al., (2011) found the presence of carbohydrate, flavonoids, phenols and tannins. Alkaloids, saponins and tannins as phytoconstituents have also been observed by Silva et al., (2013). The presence of alkaloids, reducing sugar, saponins, flavonoids, steroids, terpenoids and tannins has been observed by Suleiman (2011). Nicotiana tabacum showed anthelmintic activity against mixed infection of gastrointestinal nematodes of goats might be due to presence of tannins, alkaloids, saponins, reducing sugars, coumarins, flavonoids and triterpenes. Tannins interact with proteins in nematode cuticle which possibly changes the chemical and physical properties (Athanasiadou et al., 2007). Alkaloid may improve tonicity of gastrointestinal tracts and thus expell the worms or may have effect on nervous system (Lateef et al., 2003; Ademola et al., 2008). Saponins are naturally occurring chemical compounds found in wide variety of plants used as traditional ethanomedicinal at various concentrations.

Anthelmintic activity of saponins has been observed by Makkar et al., (2007). Conjugated unsaturated system of selected saponins is involved in the formation of free radicals, which induces membrane damage through peroxidation of membranes in helmiths (Nandi et al., 2004). Saponins enhance the cell membrane lipid peroxidation (Babu et al., 1997). About $60 \%$ of plant materials are composed of liquid, containing mostly sapogenins, the non-glycosidic portion of saponins having significant anthelmintic activity (Silveira et al., 2012).
The results of the present study clearly indicated that $N$. tabacum showed strong anthelmintic activity against different stages of gastrointestinal nematodes of goats. Therefore, it can be used as an alternative of chemical drugs in controlling gastrointestinal nematodosis in goats especially against anthelmintic resistant gastrointestinal nematodes under natural conditions.

\section{Acknowledgements}

The authors wish to express gratitude to the Director, Experiment Station and Dean, College of Veterinary and Animal Sciences, G.B. Pant University of Agriculture and Technology, Pantnagar for giving financial assistance and all the necessary facilities during the entire course of the study.

\section{References}

Ademola, I.O., Ajayi, A., and Okotie, S.V. 2008. Larvicidal effects of Aframomum danieli seed extracts against gastrointestinal nematode of sheep: in-vitro studies, African Ethnomed. Network, 5:173-179.

Athanasiadou, S., Githiori, J, and Kyriazakis, I. 2007. Medicinal plants for helminth parasite control: facts and fiction. Animal, 1:1392-1400.

Babu, Niranjan, M., Elango, K. 2011. Pharmacognostical, phytochemical and antioxidant studies of Achyranthes aspera Linn and Achyranthes bidentata Blume. J. Pharm. Res., 4:1050-1053.

Bhardwaj, P., Varshneya, C. and Sharma, V. 2015. Nematicidal activity of methanolic flower extract of Tagetes patula against Haemonchus contortus worms. Ind. J. Anim. Sci., 85:241-243.

Bhatnagar, S.S., Santapau, H., Desa, J.D.H. and Rac, T.N. 1961. Biological activity of Indian medicinal plants. Ind. J. Med. Res., 49:799-813.

Bowman, W.C., and Rand, M.J. 1980.Textbook of Pharmacology. Blackwell Scientific Publications: Oxford, 42:29-31.

Coles, G.C., Bauer, F.H.M., Borgsteede, S., 
Greerts, S., Klei, T.R., Taylor, M.A. and Waller, P.J. 1992. World Association for the Advancement of Veterinary Parasitology (WAAVP) methods for the detection of anthelmintic resistance in nematodes of veterinary importance. Vet. Parasitol, 44: 35-44.

Dash, K., Hall, K., Barger, I.A. 1988. The role of arithmetic and geometric worm egg counts in faecal egg count reduction test and in monitoring strategic drenching programs in sheep. Aust. Vet. J., 65:66-68.

Hamad, K.K., Iqbal, Z., Sindhu, Z.D. and Muhammad, G. 2012. Antinematicidal activity of Nicotiana tabacum L. Leaf extracts to control Benzimidazole resistant Haemonchus contortus in Sheep. Pak. Vet. J., 33:85-90.

Iqbal, Z., Md. Lateef, Jabbar, A., Ghayur, Md. N. and Gilani, A.H. 2006. In-vitro and in-vivo anthelmintic activity of Nicotina tabacum L. leaves against gastrointestinal nematodes of sheep. Phytotherapy Res., 20:46-48.

Kambou, G., and I.P. Guissou, I.P. 2011. Phytochemical composition and Insecticidal Effects of Aqueous Spice Extracts on Insect Pests Found on Green beans (Phaseolus vulgaris) in burkina Faso. Tropicultura, 29:212-217.

Kaushik, S., Ahmad, S. and Sharma P. 2011. Pharmacognostic evaluation and HPTLC fingerprinting of Nicotiana tabacum leaf collected from different geographical regions of India. Der Pharmacia Lettre, 3:291-300.

Kuamr, S., Kumar, A., Kumar, N., Sharma, N. Singh, M., Gopinath, D. and Gupta, V.K. (2015). In-vitro anthelmintic activity and phytochemical analysis of for tropical plants against Haemonchus contortus. Int. J. Advanced Res., 6: 541-548.

Kumar, R.R., Vatsya, S and Yadav, C.L. 2014. Invitro anthelmintic activity of Prunus persica against Haemonchus contortus. Progressive Res., 9(special issue): 466-468.

Kumar, R.R., Vatsya, S and Yadav, C.L. 2016. Anthelmintic activity and Phytochemical analysis of Chenopodium album against Haemonchus contortus. J. Vet. Sci., 2:5357.
Lateef, M., Zafar, I., Khan, M.N., Akhtar, M.S. and Jabbar, A. (2003). Anthelmintic activity of Adhatoda vesica roots. Int. J. Agri. Biol., 5:86-89.

Le Jambre, L. F., 1976. Egg hatch as an in vitro assay of thiabendazole resistance in nematodes. Vet. Parasitol., 2:385-391.

MAFF, 1971. Manual of Veterinary Parasitology Laborator Parasitology. HMSO, London. Pp.5-288.

Makkar, H.P.S., Francis, G. and Becker, K. 2007. Bioactivity of phytochernicals in some lesser-known plants and their effects and potential applications in livestock and aquaculture production systems. Anim. Sci., 1:1371-139.

Molef, N.I., Tsotetsi, A.M., Ashafa, A.O.T. and Thekisoe, O.M.M. 2013. In-vitro anthelmintic activity of Cotyledon orbiculata, Hermannia depress and Nicotiana glauca extracts against parasitic gastrointestinal nematodes of livestock. J. Med. Plants Res., 9: 536-542.

Nandi, B., Roy S., Bhattacharya, S., Babu, S.P.S. 2004. Free radicals mediated membrane damage by the saponins acaciaside $\mathrm{A}$ and acaciaside B. Phytother. Res., 18:191-194.

Neal, M.J., 2002. Medical pharmacology at a glance. Blackwell Science, Oxford, pp 88-89

Neogi, N.C., Baliga, P.A.C. and Srivastava, R.K. 1964. In-vitro anthelmintic activity of some indigenous drugs. J. Ind. Med. Res. Assoc., 41:435-437.

Nouri, F., Nourollahi-Fard, S.R., Foroodi, H.R. and Sharifi, H. 2014. In-vitro anthelmintic effect of Nicotiana tabacum extract on parasitic nematode, Marshallagia marshalli. J. Parasit. Dis., doi: 10.1007/s12639-014-0550-3.

Raje, A.A., and Jangde, C.R. 2003. In-vitro anthelmintic activity of decoction of Nicotiana tabacum against Haemonchus contortus. Ind. Vet. J., 80: 364-365.

Rialch, A., Vatsya, S. and Kumar, R.R. 2013. Detection of Benzimidazole resistance in gastrointestinal nematodes of sheep and goats of sub-Himalayan region of northern India using different tests. Vet. Parasitol, 198: 312-318.

Sangwan, N., and Sangwan, A.K. 1998. In-vitro 
effect of leaf extract of Melia azedarach on mortality of $H$. contortus. Ind. J. Anim. Res., 32:70-72.

Sanyal, P.K., 1998. Integrated parasite management in ruminants in India: A concept note. Biological control of gastro intestinal parasites of ruminants using predacious fungi, FAO Animal Production and Health Paper 141, FAO, Rome, pp. 5465.

Silva, B. E., Dalpiaz, T., Nunes, E., Ferraz, A., Martins, T.L.C., Dias, J.F. and da Rosa, D.P. 2013. Genotoxicity of Nicotiana tabacum leaves on Helix aspersa Fernanda. Genetics Molecular Biol., 36:269-275.

Silveira, R.X., Chagas, A.C.S., Botura, M.B., Batatinha, M.J.M., Katiki, L.M., Carvalho, C.O., Bevilaqua, C.M.L., Branco, A., Machado, E.A.A., Borges, S.L., Almeida, M.A.O. 2012. Action of sisal (Agave sisalana, Perrine) extract in the in-vitro development of sheep and goat gastrointestinal nematodes. Exp. Parasitol., 131:162-168.

Sindhu, Z. D., Iqbal, Z., Asim, M., Ahmad, A., Abbas, R. Z. and Bilal Aslam 2014. In-vitro ovicidal and wormicidal activity of six medicinal plants against Haemonchus contortus. Int. J. Agric. Biol., 16:11991203.

Singh, M.P., 2001. Epidemiology of haemonchosis and efficacy of some ethanomedicine plants against haemonchosis. M.V.Sc. thesis, G.B.P.U.A.
\& T. Pantnagar, Uttarakhand, India.

Singh, S., and Yadav, C.L. 1997. A survey of anthelmintic resistance by nematodes on three sheep and two goat farms in Hissar (India). Vet. Res. Communic., 21:447-451.

Smith, D. (2014). Nematode vaccines. Moredun, UK (http://www.moredun.org.uk).

Sofowara, A., 1982. Medicinal plants and traditional medicine in Africa. Chicchesfer, John Walley.

Soulsby, E.J.L., 1965. Text book of veterinary clinical parasitology vol. I. Helminths. Blackwell Scientific publication, Oxford, pp. 334-381.

Suleiman, M.N., 2011. The in vitro phytochemical investigation on five medicinal plants in Anyigba and its environs, Kogi State, Nigeria. Der Pharmacia Sinica, 2:108-111.

Swarnkar, C.P., and Singh, D. 2005. Nutritional intervention in management of gastrointestinal nematodes in small ruminants. Proceedings of FAO Symposium on Integrated Animal Parasite Management: From Academic Interest to Reality, Dept. of Parasitology. College of Veterinary Science and Animal Husbandry, Anjora, Durg, pp. 41-54.

Tyasi, T.L., Tyasi AL 2015. The efficacy of Elephantorrhiza elephantina in the ethnoveterinary medicine for gastrointestinal parasites on goats: A review. J. Agric. Econ. Ext. Rural dev., 3:283-288.

\section{How to cite this article:}

Sushmita Sastya, Rajeev Ranajan Kumar and Stuti Vatsya. 2017. Evaluation of Anthelmintic Efficacy of Nicotiana tabacum against Gastrointestinal Nematodes of Goats. Int.J.Curr.Microbiol.App.Sci. 6(10): 780-789. doi: https://doi.org/10.20546/ijcmas.2017.610.094 